\title{
Editorial: When is a ligament really a ligament?
}

Whilst Paul Segond in 1879 first reported a fibrous band of tissue passing through the lateral aspect of the knee, which tightened during forced internal rotation, it was not until Vincent [1] and Claes' [2] work in 2012 and 2013 respectively, that the anterolateral ligament (ALL) was really brought to the fore. Unsurprisingly there has been a mixture of scepticism and uncertainty regarding the existence of this structure let alone its actual role. This has, in some circles, created an aura around the ALL which has been very exciting in the world of the 'die-hard' knee lover. This has been illustrated through an explosion of publications in the last five years on the ALL with sensational titles such as "solving the mystery of the antero lateral ligament" [3] and "anterolateral ligament of the knee: myth or reality?" [4] to name but two.

The story of the ALL raises a controversial question for clinicians and anatomists alike as to when is a ligament a ligament and when it is merely a thickening of the capsule or surrounding tissues. The previous definition of a ligament is that of a non-contractile structure (non-muscular) which limits excessive movement (specific role in joint stability) and has an origin and an attachment (anatomically distinct). The ALL has been reported as having a clear and specific role in joint stability, namely restricting forced internal rotation, and there appears general agreement regarding its tibial insertion. However numerous papers have reported variability in the ALL's femoral insertion and its relationship to the lateral collateral ligament.

In this edition of The Knee, Neir et al [5] reports a histological analysis of 30 fresh-frozen cadaveric knees from 15 subjects. In this, the researchers microscopically examined the histological organisation, architecture and composition of ALL samples, comparing these to the surrounding articular capsule and the femoral insertion to the lateral collateral ligament. Histologically Neir et al [5] reported that the consistent presence of an organised central strip of dense collagen, orientated in a parallel alignment and surrounded by loose peripheral collagen fibres was indicative of a separate ligamentous structure. They reported distinct and consistent differences in the architecture of a dense collagen band and bony insertions. Whilst there was a distinction between the femoral aspect of the ALL to the lateral collateral ligament, and with a clear bone-ligament interface, the tibial aspect was less clear with no connection between the lateral tibial articular cartilage and an extra-articular localisation of the ALL.

This paper is therefore important as it provides further histological evidence of the existence of the ALL and further re-enforces the differences between the femoral and tibial attachment, the latter remaining elusive to a conventional bone-ligament interface [5]. This opens further questions around not only the ALL's mechanisms of failure but also how it may behave under load and strain when acting in synergy with surrounding tissues. However, I think these debates can await for another day.

Dr Toby Smith

Associate Editor: The Knee

Nuffield Department of Orthopaedics, Rheumatology and Musculoskeletal Sciences

University of Oxford

\section{REFERENCES}

1. Vincent JP, Magnussen RA, Gezmez F, Uguen A, Jacobi M, Weppe F, Al-Saati MF, Lustig $S$, Demey $G$, Servien E, Neyret $P$. The anterolateral ligament of the human knee: an anatomic and histologic study. Knee Surg Sports Traumatol Arthrosc. 2012 Jan;20(1):147-52. doi: 10.1007/s00167-011-1580-3. Epub 2011 Jun 30. 
2. Claes $\mathrm{S}$, Vereeche $\mathrm{E}$, Maes $\mathrm{M}$, Victor J, Verdonk $\mathrm{P}$, Bellemans J. Anatomy of the anterolateral ligament of the knee. Journal of Anatomy 2013; 223; 321-328.

3. Farhan PHS, Sudhakaran R, Thilak J. Solving the Mystery of the Antero Lateral Ligament. J Clin Diagn Res. 2017 Mar;11(3):AC01-AC04

4. Coquart B, Le Corroller T, Laurent PE, Ollivier M, Pradel V, Champsaur P, Guenoun D. Anterolateral ligament of the knee: myth or reality? Surg Radiol Anat. 2016 Oct;38(8):95562.

5. Neri T, Dalcol P, Palpacuer F, Bergandi F, Prades JM, Farizon F, Philippot R, Peoc'h M. The anterolateral ligament is a distinct ligamentous structure: $A$ histological explanation. Knee. 2018 Apr 11. pii: S0968-0160(18)30136-4. 